\title{
A Comparative Study to Assess the Physical Parameters of Newborns Delivered at term to a Mother with Pregnancy Induced Hypertension and Term Normal Pregnancy
}

\author{
Manisha Shinde Jotwar \\ Nursing Tutor, Government Nursing School, Solapur (Maharashtra), India
}

\begin{abstract}
A study to assess the physical parameters of newborns delivered at term to a mother with pregnancy induced hypertension and term normal pregnancy and, descriptive approach and A non-experimental research design was used. The study was conducted in selected hospital in the district.The sample was 100 (50 newborns of P.I.H mothers \& 50 newborns of mothers with normal pregnancy). Convenient sampling technique was used in the study to collect subjects. Findings - In newborns delivered at term of mother with pregnancy induced hypertensive mothers. $2 \%$ of the newborns had poor physical health (score 1-4), $42 \%$ of them had fair physical health (score 5-10) and 56\% of them had good physical health (Score 11-15). In physical parameters of physical parameters of newborns delivered at term of mother with normal pregnancy, none of the newborns had poor physical health (score 1-4), 16\% of them had fair physical health (score 5-10), 74\% of them had good physical health (Score 11-15) and 10\% of them had very good physical health (Score 16-20). The physical health of the newborns delivered at term of mother with normal pregnancy was better than the newborns delivered at term of mother with pregnancy induced hypertensive mothers.
\end{abstract}

Keywords: physical parameters, newborns, pregnancy induced hypertension, full term

\section{Introduction}

Learning is the addition of new knowledge and experience Interpreted in the light of past knowledge and experience. Teaching and learning is an integral part of nursing. Nurses have the responsibility to educate patients related to various aspects and keep themselves updated. Various teaching strategies are used to increase knowledge, such as lecturing, demonstration, discussion and self-education. These methods of self-education has an advantage over the others as the learner can educate himself at his own pace and it also stresses on rereading [1].

Pregnancy-induced hypertension (PIH), especially preeclampsia, is a major cause of maternal and perinatal morbidity and mortality worldwide [2].

The impact of PIH on birth outcomes has been extensively studied. However, the potential long-term effect of PIH on infants born to PIH mothers has been less studied. PIH has been confirmed to increase significantly the risk of low birth weight by both increasing preterm birth as well as reducing fetal growth. On the other hand, PIH has been found to be associated with an increased rate of high birth weight and large-for-gestational age babies[11].

PIH may have different short and long term effects on infant growth between these possible two types of preeclampsia by intrauterine growth restriction (IUGR) [12]..$^{14}$ Low birth weight or IUGR babies have been associated with the occurrence of several chronic diseases such as cardiovascular diseases in later life[13].
Hypothesis of the fetal origins of adult disease is still the subject of debate[14]. ${ }^{16}$ One argument is that maternal risk factors in pregnancy (such as PIH) and environmental risk factors in the postpartum period can contribute to this lifelong development of the chronic disorders. A change in infant growth of the IUGR baby itself (e.g. catch-up growth) such as in the critical early infant period may also have longterm effects on health later in life, and this change of postpartum growth may be influenced by PIH[15]. It is important to study postpartum infant growth patterns of babies born to mothers with PIH, and to determine if there are differences in infant growth between babies with and without IUGR. However, to date, there have been few studies on the effects of PIH on infant growth. The objective of this study was to examine the effects of the various types of PIH on infant weight gain at 28 and 42 days postpartum. High blood pressure complicates almost 10 percent of all pregnancies, and the incidence is higher if the women are nulliparous or carrying multiple fetuses. Preeclampsia is a major cause of maternal mortality in developed and developing countries. It is also a major cause of perinatal morbidity and mortality, and it is very strongly associated with fetal growth retardation [16].

\section{Efficacy of Study}

Kadam A. (2014) found that Structured education programme was highly effective to improve the knowledge score and to improve the attitude score of subjects/ caregiver towards colostomy care of patient [4]. Anjum,S.(2014)conducted study to assess knowledge of contraceptives methods and appraisal of health education among married women and concluded After the health education married women knowledge was improved to $100 \%$ about female sterilization followed by condom $99 \%$, skin 


\section{International Journal of Science and Research (IJSR) ISSN (Online): 2319-7064}

Index Copernicus Value (2013): 6.14 | Impact Factor (2014): 5.611

implants $86 \%$, oral pills $85 \%$ and emergency contraceptives $85 \%$.Sociodemographic variable were significantly associated with existing knowledge and level of married women specially age at marriage, age at first child, occupation,, income ,education [5][6]. Babu, R. L. (2014) The findings of the study concluded that care takers had inadequate knowledge regarding non-curative care of terminally ill cancer patients. The planned education programme on non-curative care of terminally ill cancer patients was highly effective in improving the knowledge of care takers regarding non-curative care of terminally ill cancer patients.[7] Shinde,M.(2014) concluded that demonstration regarding feeding of hemiplegic patient among caregivers was effective in increasing the skill of the caregivers regarding feeding of hemiplegic patient [8].

Deshmukh, M., \& Shinde, M. (2014). concluded that the structured education was effective on knowledge and practice of staff nurses regarding venous access device care[9]. Bhudhagaonkar, J., \& Shinde, M. (2014). Concluded that Structured Education Regarding Menstrual Hygiene Practices was effective among Adolescent Girls.[10]

\section{The Normal Newborn}

The average duration of pregnancy is 40 weeks. A baby born after this period weighs $2.8 \mathrm{~kg}$. (On an average).Any newborn with a birth weight of $<2.5 \mathrm{~kg}$. is classified as a low birth weight baby and needs special care. Following are the characteristics of a normal newborn baby: Weight $2.5-3.5$ $\mathrm{kg}$, Length $50 \mathrm{~cm}$. Head circumference $35 \mathrm{~cm}$, Heart rate 120 - 140 beat per minute. Respiratory rates 30 - 40 Breaths per minute[17].

\section{Impact of the Maternal Health on Newborn}

The kind of lifestyle an expectant mother has or any particular kind of health conditions that she may be suffering from will have effect on the baby's health and weight. A lowweight newborn can be due to the fact that the mother is suffering from hypertension, heart ailments or she may have been smoking, having alcohol or illicit use of drugs during her pregnancy. Many women suffer from diabetes or get gestational diabetes during pregnancy which can make the baby large for gestational age and weigh more than normal. The obstetrician needs to monitor a baby's growth and progress in the womb and any factors which can affect the baby's weight or general health should be taken care of[18].

\section{Fetal Impact}

Perinatal outcome is strongly influenced by gestational age and the severity of hypertension as expressed by the need for antihypertensive treatment, irrespective of the underlying syndrome. Severe preeclampsia is associated with different degrees of fetal injury. The main impact on the fetus is under nutrition as a result of utero-placental vascular insufficiency, which leads to growth retardation. There are short and longterm effects. The immediate impact observed is altered fetal growth resulting in greater fetal liability. Fetal health as well as its weight is highly compromised, leading to various degrees of fetal morbidity, and fetal damage may be such as to cause fetal death. Long term follow up studies have demonstrated that babies who suffered intrauterine growth retardation are more likely to develop hypertension, coronary artery disease, and diabetes in adult life [19].

\section{Maternal Impact}

Women who have or develop high blood pressure during pregnancy are all at increased risk of complications antenatally, intrapartum and in the puerperium. The increased risk applies to the mother as well to the fetus. Pregnant women with hypertension can be divided into two groups: normotensive women who develop the preeclampsia syndrome, which is characterized by hypertension, proteinuria, and oedema; and women with chronic hypertension who become pregnant and are at a higher risk of developing superimposed preeclampsia [20].

The impact of preeclampsia affects both mother and fetus, but it is important to differentiate between the complications of the disease from those inevitably associated to the drugs used for its treatment. Preeclampsia is the most serious form of hypertensive pregnancy complications, but it is not primarily a hypertensive disease; it is a disorder induced by factors based on the presence of placenta. Preeclampsia is initiated by abnormal placentation. Release of cytokines and other toxins, and vasoconstriction and platelet activation; so it is a syndrome of generalized endothelial dysfunction, and the complications are associated with the vascular system. Fundamentally, these complications are 1- intravascular coagulation, bleeding and 2- organ failure (hepatic and renal) following poor perfusion [21].

Pregnancy induced hypertension (P.I.H) which includes preeclampsia and eclampsia are the most common medical complication reported during pregnancy. A significant contributor to maternal and perinatal morbidity and mortality complicates approximately 12 to 20 percent of all pregnancies not terminating in first trimester miscarriages, depending on the populations and definitions used. The rate of pregnancy related hypertension has raised steadily, current rate of 38.8 per 1000 live births. By about $30 \%$ to $40 \%$, since 1990 for all ages, races, and ethnic groups to the current rate of 38.8 per 1000 live births[22]

Preeclampsia is a well-known cause of perinatal mortality. Despite remarkable improvements in clinical management, preeclampsia often culminates in the delivery of a very preterm infant following medical intervention. Even mild preterm delivery substantially increases the risk of neonatal death. Therefore, when preeclampsia occurs early in pregnancy, even a few additional days in utero may be key to a newborns survival[22].

A review of clinical trials of delayed vs. immediate delivery in fact suggested better outcome with delayed delivery in well-selected patients On the other hand; preeclampsia can progress rapidly, putting both mother and child at severe risk if no action is taken [22].

Preeclampsia occurs primarily after the second trimester of pregnancy, representing a greater danger to the fetus and neonate. Eclampsia from profound cerebral effects of preeclampsia is the major maternal hazard. Preeclampsia 


\section{International Journal of Science and Research (IJSR) \\ ISSN (Online): 2319-7064}

Index Copernicus Value (2013): 6.14 | Impact Factor (2014): 5.611

contributes significantly to intrauterine fetal death and perinatal mortality. Causes of perinatal death related to preeclampsia are utero-placental insufficiency and abruption of placenta which leads to intrauterine death, preterm birth and low birth weight. So providing safe and effective care for the client at high risk requires a joint effort from all members of the health care team, with each member contributing unique skills and talents to provide optimal outcomes for mother and infant. [22]

\section{Problem Statement}

A comparative study to assess the physical parameters of newborns delivered at term to a mother with pregnancy induced hypertension and term normal pregnancy in selected hospital.

\section{Objectives of Study:}

1)To assess the physical parameters of at term newborns delivered to a mother with pregnancy induced hypertension.

2)To assess the physical parameters of at term newborns delivered to a mother with normal pregnancy.

3)To compare the physical parameters of newborns delivered at term of mother with normal pregnancy and pregnancy induced hypertensive mother.

\section{Research Methodology}

Methodology is the framework used to conduct the study. It includes the research design, the setting, population, sample and sample size, sampling technique, development and description of tool, validity and reliability, pilot study, data gathering process and plan for data analysis.[3]

\section{Research Approach}

In the view of the nature of the problems selected and to accomplish the objectives of the study a quantitative, descriptive approach is considered to compare the physical parameters of newborns delivered at term of mother with normal pregnancy and pregnancy induced hypertensive mothers in selected hospitals.

\section{Research Design}

A non-experimental research design was used for this study.

\section{Setting of the Study}

The study was conducted in selected hospital in the district to insure the availability of required numbers of samples.

\section{Samples}

The sample from the present study was 100 samples (50 newborns of P.I.H mothers \& 50 newborns of mothers with normal pregnancy)

\section{Sampling Technique}

Convenient sampling technique was used in the study to collect subjects.

\section{Development \& Description of Tool}

Section I : The demographic data -It consist of demographic information of the mother.
Section II: Consist of clinical profile of mother.

Section III : Consists of physical assessment of newborn.

\section{Following Steps Were Used to Prepare the Tool}

\section{1)Review of related literature}

2)Preparation of blue print of tool

3)Consultation \& verification of tool from experts of concerned fields.

\section{Pilot Study}

A Pilot study was conducted on $10 \%$ of sample (5 newborns of P.I.H mothers \& 5 newborns of mothers with normal pregnancy). The data was analyzed using descriptive and inferential statistics.

\section{Validity and Reliability}

The tool was further modified as per suggestions of the expert and final tool was constructed. Validity of tool will be done by 22 expertise', who are expert in their respective field. After consulting guide and statistician final tool was reframed.

Reliability of tool was statistically measured by using Interrater method. Pearson's correlation coefficient was found to be 0.97 , hence the tool found to be reliable.

\section{Data Collection Procedure}

The data gathering process started from $11^{\text {th }}$ October 2013 and ended on $31^{\text {st }}$ October 2013, after getting the required permission from the respective authorities. And the written consent will be obtained from the mothers of newborn with P.I.H. and normal pregnancy. From the respondents indicating their willingness to participate in the study. Subjects who fulfilled the sampling criteria were taken from the selected hospital by using non-probability convenient sampling technique by using Observation checklist. Data collection done and scoring was done at the time of session only.

\section{Plan for Statistical Analysis}

The data will be entered in to the master sheet keeping objectives of the main study in view, the descriptive an inferential statistics was done.

\section{Findings of the Study and Discussion}

The major findings of the study are summarized as follows:

a) Physical health score of newborns delivered at term P.I.H. mothers group, $2 \%$ of the newborns had poor physical health (score $1-4$ ), $42 \%$ of them had fair physical health (score 5-10) and 56\% of them had good physical health (Score 11-15).

b)Sex wise distribution of newborns delivered at term P.I.H. mothers group, majority of $58 \%$ at term newborns delivered to a mother with pregnancy induced hypertension were females and $42 \%$ of them were males.

c) Placement immediately after birth of newborns delivered at term P.I.H. mothers group, Majority of $72 \%$ of term P.I.H. mothers newborn were placed 


\section{International Journal of Science and Research (IJSR)}

ISSN (Online): 2319-7064

Index Copernicus Value (2013): 6.14 $\mid$ Impact Factor (2014): 5.611

immediately after birth with mother and $28 \%$ of them were placed in NICU immediately after birth.

d) Vital signs of at term newborns delivered to a mother with pregnancy induced hypertension

- Average temperature of the at term newborns delivered to a mother with pregnancy induced hypertension is $97.6^{\mathrm{O}} \mathrm{F}$ with standard deviation of 0.4 .

- Average respiratory rate of the term newborns delivered to a mother with pregnancy induced hypertension is $51.3 /$ minute with standard deviation of 4.3 .

- Average heart beats/minute of the term newborns delivered to a mother with pregnancy induced hypertension is 150.6 with 5.6 of standard deviation.

e) Physical parameters of at term newborns delivered to a mother with pregnancy induced hypertension.

- Average birth weight of the term newborns delivered to a mother with pregnancy induced hypertension is 2400 Gms. with standard deviation 378.4.

- Average length (height) of the term newborns delivered to a mother with pregnancy induced hypertension is 47.4 $\mathrm{cm}$ with standard deviation of 2.3.

- Average head circumference was $32.2 \mathrm{~cm}$ with standard deviation of 1.4

- Average chest circumference was $31 \mathrm{~cm}$ with standard deviation of 1.5 .

f) Physical health score of newborns delivered at term newborns delivered to a mother with normal pregnancy.

- In Normal pregnancy mothers group, none of the newborns had poor physical health (score 1-4), 16\% of them had fair physical health (score $5-10), 74 \%$ of them had good physical health (Score 11-15) and 10\% of them had very good physical health (Score 16-20).

g)Sex wise distribution of newborns delivered at term newborns delivered to a mother with normal pregnancy, majority of $54 \%$ of at term newborns delivered to a mother with normal pregnancy were females and $46 \%$ of them were males.

h) Placement immediately after birth wise distribution of newborns delivered at term newborns delivered to a mother with normal pregnancy, Majority of term newborns delivered to a mother with normal pregnancy $98 \%$ were placed immediately after birth and $2 \%$ of them were placed in NICU immediately after birth.

i) Vital signs of at term newborns delivered to a mother with normal pregnancy,

- Average temperature of the term newborns delivered to a mother with normal pregnancy was 97.6OF with standard deviation of 0.6 .

- Average respiratory rate of them was $48 /$ minute with standard deviation of 2.8 .

- Average heart beats/minute was 148.2 with 2.8 of standard deviation.

j) Physical parameters of at term newborns delivered to a mother with normal pregnancy,

- Average birth weight was $2824 \mathrm{Gms}$ with standard deviation 373.8 .

- Average length (height) was $48.3 \mathrm{~cm}$ with standard deviation of 2.5 .

- Average head circumference was $33.6 \mathrm{~cm}$ with standard deviation of 1.1 .
- Average chest circumference was $31.9 \mathrm{~cm}$ with standard deviation of 1.3 .

k)Comparison of physical health of newborns delivered at term of mother with normal pregnancy and term pregnancy induced hypertensive mothers.

In newborns delivered at term of mother with pregnancy induced hypertensive mothers. $2 \%$ of the newborns had poor physical health (score 1-4), 42\% of them had fair physical health (score 5-10) and 56\% of them had good physical health (Score 11-15). In physical parameters of physical parameters of newborns delivered at term of mother with normal pregnancy, none of the newborns had poor physical health (score 1-4), 16\% of them had fair physical health (score 5-10), 74\% of them had good physical health (Score 11-15) and 10\% of them had very good physical health (Score 16-20). The physical health of the newborns delivered at term of mother with normal pregnancy was better than the newborns delivered at term of mother with pregnancy induced hypertensive mothers.

l) Two sample $z$ tests for comparison of physical health of newborns delivered at term of mother with normal pregnancy and pregnancy induced hypertensive mothers.

Researcher applied two sample z-tests for comparison of physical health of comparison of physical parameters of newborns delivered at term of mother with normal pregnancy and term pregnancy induced hypertensive mothers and newborn of normal pregnancy mothers. Average physical health score for term newborn of P.I.H. mothers was 10.66 which were 12.7 for the term newborn of mothers with normal pregnancy group. The calculated value of $\mathrm{z}$ for this comparison was 2.04 at 98 degrees of freedom. The corresponding table $z$ value was 1.96 . Since tabulated value is smaller than the calculated $z$-value, the null hypothesis is rejected. The physical health of the newborns of mothers with normal pregnancy group was significantly higher than that for the newborn with at term PIH mothers group.

\section{Conclusion of Research Studies}

The main aim of the study was to compare the physical parameters of newborns delivered at term of mother with normal pregnancy and pregnancy induced hypertensive mothers in selected hospitals.

The following conclusions are drawn on the basis of findings of study.

a) In newborns delivered at term of mother with pregnancy induced hypertensive mothers. $2 \%$ of the newborns had poor physical health (score 1-4), 42\% of them had fair physical health (score 5-10) and 56\% of them had good physical health (Score 11-15).

b)In physical parameters of physical parameters of newborns delivered at term of mother with normal pregnancy, none of the newborns had poor physical health (score 1-4), 16\% of them had fair physical health (score 5-10), 74\% of them had good physical health (Score 11-15) and 10\% of them had very good physical health (Score 16-20). 


\section{International Journal of Science and Research (IJSR) \\ ISSN (Online): 2319-7064}

Index Copernicus Value (2013): 6.14 | Impact Factor (2014): 5.611

c) The physical health of the newborns delivered at term of mother with normal pregnancy was better than the newborns delivered at term of mother with pregnancy induced hypertensive mothers.

d) Researcher applied two sample z-tests for comparison of physical health of comparison of physical parameters of newborns delivered at term of mother with normal pregnancy and term pregnancy induced hypertensive mothers and newborn of normal pregnancy mothers. Average physical health score for at term newborn of P.I.H. mothers Was 10.66 which was 12.7 for the term newborn of mothers with normal pregnancy group. The calculated value of $\mathrm{z}$ for this comparison was 2.04 at 98 degrees of freedom. The corresponding table $\mathrm{z}$ value was 1.96. Since tabulated value is smaller than the calculated $\mathrm{z}-$ value, the null hypothesis is rejected. The physical health of the newborns of mothers with normal pregnancy group was significantly higher than that for the newborn with at term PIH mothers group.

\section{Nursing Implication}

\section{a) Nursing Education}

The result of study and the recommendation can be motivating the nursing educator to include the topic of study in the nursing syllabus as important topic. So when they become the professional nurse like nurse clinician, nurse advocate, case agent, case manager community health nurse, pediatric nurse ,nurse midwife, nurse educator, they can able to apply their knowledge to protect such large population from complication of pregnancy Induced Hypertension. It will definitely reduce and control the incidence and prevalence of this complication in the community at primary level and protect the big and vulnerable population. It will definitely reduce perinatal mortality and morbidity rate of the Pregnancy Induced Hypertensive mothers from associated obstetrical complication \& improve the pregnancy \& pregnancy outcome.

\section{b) Nursing Service}

The community health nurse, pediatric nurse, nurse clinician, nurse midwife can become more conscious towards the complication of Pregnancy Induced Hypertension like I.UG.R, Low birth weight, small for date, premature labour, pre-eclampsia and eclampsia. This will be very crucial and precious time to make aware the Pregnancy Induced Hypertensive mothers by providing health education to reduce the chances of complication.

\section{c) Nursing Administration}

The findings of the study are of particular importance to nurse administrator in formulation of policies and protocols in providing in- service education to nursing personnel. It is the nurse's responsibility to provide promotive, preventive. Curative and rehabilitative health services to the Pregnancy Induced Hypertensive mothers and newborn of them in the clinical field \& in the community which will help for at various level in the community and hospital.

\section{d) Nursing Research}

The nurse researcher can use the findings of this study as base line data to conduct large international research to assess the comparison of Pregnancy Induced Hypertension and its neonatal outcome.

\section{Personal Experiences}

It was challenging for investigator to explore the knowledge of Pregnancy Induced Hypertensive mothers regarding neonatal outcome and fetal complication due to P.I.H. and unawareness regarding preventive, safety protective measures during antenatal, intranatal and postnatal care. The knowledge of pregnancy induced hypertensive mothers was not significantly associated with their selected demographic variables such as birth weight, length (height), Head circumference, Chest circumference etc. This experience gives me big opportunity to develop certain qualities as well as skill to investigate the one of the aspect comparison between Pregnancy Induced Hypertension and physical parameters.

\section{Limitation}

1) The study was carried out on a small population so the findings cannot be generalized for a large population.

2)The relevant literature was scanty, as hardly any nursing study has been conducted on the topic under investigation.

3) The study is limited to population, women having at term pregnancy.

4) The study was limited to the experience level of the investigate.

\section{Scope of the Study}

This study will definitely focus on mother and child health among Pregnancy Induced Hypertensive mothers group, which is large group of high-risk pregnancy and also prepare a base to motivate \& make them aware about use of precautionary and safety measures for Pregnancy Induced Hypertension, as well as aware them for antenatal care, along with importance of institutional delivery. Referral services at grass root level, and also prevent the maternal and perinatal morbidity and mortality among Pregnancy Induced Hypertensive mothers group. Apart from this;

1) The nurse educator should educate the peripheral level health worker nursing care to at term newborns delivered to a mother with Pregnancy Induced hypertension.

2)To enhance the knowledge of nursing staff, nursing student who are working in Labour room, Antenatal ward and postnatal ward give the nursing care to at term newborns delivered to a mother with Pregnancy Induced hypertension.

3) To prenatal mother with Pregnancy Induced hypertension to improve their knowledge regarding nursing care of a newborns.

4) To give the nursing care to term newborns delivered to a mother with Pregnancy Induced hypertension 


\section{International Journal of Science and Research (IJSR)}

ISSN (Online): 2319-7064

Index Copernicus Value (2013): 6.14 | Impact Factor (2014): 5.611

\section{Recommendations for Research}

- A similar study can be undertaken with larger sample: there by findings can be more generalized for large population.

- A descriptive study to assess the prevalence of Pregnancy Induced Hypertension and its neonatal outcome.

- A comparative study to assess the Pregnancy Induced Hypertension and its neonatal outcome.

- A similar study can be conducted by using a Self Instructional Module for educating the women of Pregnancy Induced Hypertension from $1^{\text {st }}$ to $3^{\text {rd }}$ trimester.

- A study can be conducted to compare the effectiveness of the information booklet for educating the women of Pregnancy Induced Hypertension from $1^{\text {st }}$ to $3^{\text {rd }}$ trimester.

A retrospective study to assess the effect of Pregnancy Induced Hypertension on growth and development among their children's.

\section{References}

[1] Shinde, M., \&Anjum, S. (2007). Educational Methods and Media for Teaching in Practice Of Nursing. Sneha Publication India (Dombivili)

[2] D Elakkuvana Bhaskaraj Raj Nursing Research and biostatistics $2^{\text {nd }}$ edition EMMESS medical publisher pg.no- 286-287.

[3] SHINDE, M., \& ANJUM, S. (2007). Introduction to Research In Nursing. Sneha Publication India(Dombivili).

[4] Kadam, A., \& Shinde, M. B. (2014). Effectiveness of Structured Education on Caregiver's Knowledge and Attitude Regarding Colostomy Care. International Journal of Science and Research (IJSR), 3(4), 586-593.

[5] Anjum, S., Durgawale, P. M., \& Shinde, M. (2014). Epidemiological Correlates of Use of Contraceptives Methods and Appraisal of Health Education on Status of Knowledge and Practices among Married Woman. International Journal of Science and Research (IJSR), 3(2), 203-210

[6] Anjum, S., Durgawale, P. M., \& Shinde, M. (2014). Knowledge of Contraceptives Methods and Appraisal of Health Education among Married Woman. International Journal of Science and Research (IJSR), 3(3), 584-590.

[7] Babu, R. L., Mali, N., \& Shinde, M. (2014). Effectiveness of Planned Teaching Programme on Knowledge Regarding Non-Curative Care of Terminally ILL Cancer Patients among Care Takers. International Journal of Science and Research (IJSR), 3(4), 198-205.

[8] Shinde, M., \& Anjum, S. (2014). Effectiveness of Demonstration Regarding Feeding of Hemiplegia Patient among Caregivers. International Journal of Science and Research (IJSR), 3(3), 19-27.

[9] Deshmukh, M., \& Shinde, M. (2014). Impact of Structured Education on Knowledge and Practice Regarding Venous Access Device Care among Nurses. International Journal of Science and Research (IJSR), 3(5), 895-901.

[10] Bhudhagaonkar, J., \& Shinde, M. (2014). Impact of Structured Education Regarding Menstrual Hygiene
Practices among Adolescent Girls. International Journal of Science and Research (IJSR), 3(5), 244-252.

[11]Daffary N Shirish, Chakarawarty Sudip, Manual Of Obstetrics, $2^{\text {nd }}$ Edition, Elsevier India Private Ldt.2005, Hypertensive disorders of pregnancy, p 99.

[12] Daffary N Shirish, Chakarawarty Sudip, Manual Of Obstetrics, $2^{\text {nd }}$ Edition, Elsevier India Private Ldt.2005, Hypertensive disorders of pregnancy, p 99.

[13] Datta Parul, Pediatric Nursing, IInd edition, New Delhi, Jaypee Brothers Medical Publishers (P) Ltd; 2009. P 66 $-67,104$.

[14]Daffary N Shirish, Chakarawarty Sudip, Manual Of Obstetrics, $2^{\text {nd }}$ Edition, Elsevier India Private Ldt.2005, Hypertensive disorders of pregnancy, p 99.

[15]Daffary N Shirish, Chakarawarty Sudip, Manual Of Obstetrics, $2^{\text {nd }}$ Edition, Elsevier India Private Ldt.2005, Hypertensive disorders of pregnancy, p 99.

[16]Daffary N Shirish, Chakarawarty Sudip, Manual Of Obstetrics, $2^{\text {nd }}$ Edition, Elsevier India Private Ldt.2005, Hypertensive disorders of pregnancy, p 99.

[17]Daffary N Shirish, Chakarawarty Sudip, Manual Of Obstetrics, $2^{\text {nd }}$ Edition, Elsevier India Private Ldt.2005, Hypertensive disorders of pregnancy, p 99.

[18]Daffary N Shirish, Chakarawarty Sudip, Manual Of Obstetrics, $2^{\text {nd }}$ Edition, Elsevier India Private Ldt.2005, Hypertensive disorders of pregnancy, p 99.

[19] Ghai O.P., Gupta Piyush 2004,Essential pediatrics,CBS Publishers and distributors, New Delhi, Sixth edition,Page No.1314-1384.

[20] Ignatavicius D D, Workman W L et al. Medical Surgical Nursing. $2^{\text {nd }}$ edition. Philadelphia: W.B. Sunders Company; 1995. 101-16

[21] Krishna Usha, Tank D K, Dftary Prganancy at Risk current concept, $4^{\text {th }}$ edition, New Delhi,Jypee brothers medical publishers (p)Ltd. 2001, PIH current concept, p 257,259,.264-265.

[22] Lowdermilk perry, maternity and woman health care; 8th edition, Mosby publication; US 2000: p 838-843.

[23] Myles Margaratte Textbook for Midwives. Churchill livingstone an inprint of Harcourt publishers. 2004. Page no.: 315-328.

\section{Author Profile}

Manisha Shinde, Nursing Tutor, Govt NSG School Solapur 